\title{
Radiosurgery: Fair Treatment Option for Inoperable Brain Vascular Lesions
}

\author{
Roman Liscak $^{\mathrm{a}} \quad$ Josef Vymazal ${ }^{\mathrm{b}}$ \\ aDepartment of Stereotactic and Radiation Neurosurgery, Na Homolce Hospital, Prague, Czech Republic; \\ ${ }^{b}$ Department of Radiology, Na Homolce Hospital, Prague, Czech Republic
}

\section{Dear Editor,}

We appreciate the enrichment of discussion on our article by M. Tripathi. We are pleased to read that the results of radiosurgery for AVMs are considered spectacular; indeed, the chance to cure small AVMs with a nidus $<3 \mathrm{~cm}$ in diameter is $>90 \%$, although this is achieved in some patients after repeated treatment [1]. Radiosurgery of vascular lesions faces the drawback of delayed effect after a latency period; therefore, patients benefit from immediate cure after microsurgery or embolization. Unfortunately, curative and safe microsurgery cannot be performed in all patients, and radiosurgery primarily involves inoperable vascular lesions. Radiosurgery is thus humbly applied to select patients who could be healed without unacceptable risks. The chance to cure large AVMs after staged radiosurgery is $39 \%$ [2]. Statistically, the risk of rebleeding is reduced for cavernomas after the latency period [3]. Although these results may not be exciting, they are fair.

Aneurysms remain on the periphery of radiosurgery, but this treatment method can be helpful in specific situations even for these patients. We agree that it cannot be concluded that radiosurgery actually causes an aneurysmal obliteration, and our case series does not provide a direct answer to this question. On the contrary, we con- clude that radiosurgery of distal aneurysms relies on obliteration of the feeding artery, fortunately without sequela. However, the effect of radiosurgery on berry aneurysms is currently of increasing interest. Although histological changes of the aneurysm wall have been observed after radiosurgery [4], further studies are needed to demonstrate its potential effect on risk of hemorrhage, which are under way. Currently, radiosurgery is not used for aneurysms of the circle of Willis or proximal arteries.

\section{Acknowledgement}

This study was supported by MH CZ-DRO (NHH, 00023884).

\section{Conflict of Interest Statement}

R.L. is a consultant to Elekta AB. J.V. has no conflicts of interest to declare.

\section{Author Contributions}

Conception and design: Liscak and Vymazal. Drafting the article: Liscak. Critical revision and review of the article: Liscak and Vymazal.
Correspondence to:

Roman Liscak, roman.liscak@ homolka.cz 


\section{References}

1 Liscak R, Vladyka V, Simonova G, Urgosik D, Novotny J Jr, Janouskova L, et al. Arteriovenous malformations after Leksell gamma knife radiosurgery: rate of obliteration and complications. Neurosurg. 2007 Jun;60(6): 1005-14.
2 Chytka T, Liscak R, Kozubiková P, Vymazal J. Radiosurgery for large arteriovenous malformations as a single-session or staged treatment. Stereotact Funct Neurosurg. 2015; 93(5):342-7.

3 Liscak R. Radiosurgery of brain cavernomas: long-term results. In: Niranjan A, Kano H, Lunsford LD, editors. Gamma knife radiosurgery for brain vascular malformations. Progress in neurological surgery. Basel: Karger; 2013. Vol. 27; p. 147-56.
4 Meadowcroft MD, Cooper TK, Rupprecht S, Wright TC, Neely EE, Ferenci M, et al. Gamma Knife radiosurgery of saccular aneurysms in a rabbit model. J Neurosurg. 2018 Dec 1; 129(6):1530-40. 